TEACHING TACTIC

\title{
Does This Sound Religious?
}

\author{
Amy DeRogatis \\ Michigan State University \\ Isaac Weiner \\ The Ohio State University
}

\section{The context}

An introductory undergraduate religious studies course with students from a variety of majors. We teach at large, midwestern state universities. This strategy could probably be adapted for any size classroom, but the professor might not be able to incorporate every student response.

\section{The pedagogical purpose}

This activity introduces students to the central question in the study of religion: how does one define religion? The tactic, which could be paired with an introductory lecture on classical definitions of religion, provides students with the opportunity to discuss definitions of religion and specifically, to take seriously the scholar's role in creating definitional boundaries. It also invites students to reflect on the differences between engaging with religion through aural sources rather than textual or visual ones. Finally, it helps students reflect on whether scholars privilege some sensory forms of knowledge (seeing, feeling/experiencing) over others (hearing) in their definitions of religion, and how aural sources might provide different insights into the nature of religion.

\section{Description of the strategy}

This tactic requires instructors and students to use the American Religious Sounds Project database. ${ }^{1}$ Prior to class, students review audio clips in the ARSP Archive $^{2}$ and choose one example of a sound clip that they think: (1) is religious; (2) might be religious; and (3) is not religious (for example, a metaphysical healing expo $^{3}$ or a political protest ${ }^{4}$ ). Divide students into pairs to discuss their three clips for fifteen minutes or so, comparing and explaining their choices to each other. Then ask each pair to list their audio files in three columns on the board (religious, might be religious, not religious). Discuss the reasons for their placements:

- Why do you think clip $\mathrm{x}$ is a religious sound? What do you expect religion to sound like?

- What makes a sound religious? Who decides?

- What types of information do you need to label a sound religious? What information do you need that you don't have?

- Give a compelling argument for why clip x should switch columns.

- Would it be easier to decide if something were religious by reading a text or looking at an object? How does hearing a practice differ from reading about it or watching it?

- How does this classroom activity relate to the study of religion?

\section{Why it is effective}

This activity requires students to go through the process of making choices about which sounds count as religious and then to explain their choices. Rather than lecturing to students about how definitions of religion are always interpretive choices, this activity engages them in the process. Their debates replicate those in the field and demonstrate that students (like scholars) bring their own experience and knowledge to the classroom that influences how they think about religion.

1 http://religioussounds.osu.edu/ (accessed 14 August 2019).

2 https://explore.religioussounds.osu.edu/visualization?show_popup=true\&skip_control_ screen=true\&target_visualization=archive.

3 https://explore.religioussounds.osu.edu/public/recordings/127.

4 https://explore.religioussounds.osu.edu/public/recordings/122. 